\title{
Effect of dissolved oxygen on redox potential and milk acidification by lactic acid bacteria isolated from a DL-starter culture
}

\author{
Nadja Larsen, ${ }^{1,2}$ Birgit Brøsted Werner, ${ }^{1}$ Finn Kvist Vogensen, and Lene Jespersen \\ Department of Food Science, Food Microbiology, University of Copenhagen, Rolighedsvej 26, DK-1958 Frederiksberg C, Denmark
}

\begin{abstract}
Milk acidification by DL-starter cultures [cultures containing Lactococcus lactis diacetylactis (D) and Leuconostoc (L) species] depends on the oxidation-reduction (redox) potential in milk; however, the mechanisms behind this effect are not completely clear. The objective of this study was to investigate the effect of dissolved oxygen on acidification kinetics and redox potential during milk fermentation by lactic acid bacteria (LAB). Fermentations were conducted by single strains isolated from mixed DL-starter culture, including Lactococcus lactis ssp. lactis, Lactococcus lactis ssp. cremoris, and Leuconostoc mesenteroides ssp. cremoris, by the DLstarter culture, and by the type strains. High and low levels of oxygen were produced by flushing milk with oxygen or nitrogen, respectively. The kinetics of milk acidification was characterized by the maximum rate and time of acidification $\left(\mathrm{V}^{\mathrm{a}}{ }_{\max }\right.$ and $\left.\mathrm{T}^{\mathrm{a}}{ }_{\max }\right)$, the maximum rate and time of reduction $\left(\mathrm{V}^{\mathrm{r}}{ }_{\max }\right.$ and $\left.\mathrm{T}^{\mathrm{r}}{ }_{\max }\right)$, the minimum redox potential $\left(\mathrm{E}_{\mathrm{h} 7 \text { final }}\right)$, and time of reaching $\mathrm{E}_{\mathrm{h} 7 \text { final }}\left(\mathrm{T}_{\text {final }}^{\mathrm{r}}\right)$. Variations in kinetic parameters were observed at both the species and strain levels. Two of the Lc. lactis ssp. lactis strains were not able to lower redox potential to negative values. Kinetic parameters of the DL-starter culture were comparable with the best acidifying and reducing strains, indicating their additive effects. Acidification curves were mostly diauxic at all oxygen levels, displaying 2 maxima of acidification rate: before (aerobic maximum) and after (anaerobic maximum) oxygen depletion. The redox potential decreased concurrently with oxygen consumption and continued to decrease at slower rate until reaching the final values, indicating involvement of both oxygen and microbiological activity in the redox state of milk. Oxygen flushing had a negative effect on reduction and acidification capacity of tested LAB. Reduction was significantly delayed at high initial oxygen, exhibiting longer $\mathrm{T}_{\text {max }}^{\mathrm{r}}, \mathrm{T}_{\text {final }}^{\mathrm{r}}$, or both. Concurrently, anaerobic
\end{abstract}

Received October 13, 2014.

Accepted November 25, 2014.

${ }^{1}$ These authors contributed equally to the publication.

${ }^{2}$ Corresponding author: nf@food.ku.dk acidification rate maximum $\mathrm{V}^{\mathrm{a}}{ }_{\max }$ was decreased and $\mathrm{T}_{\text {max }}^{\mathrm{a}}$ was extended. Fermentation kinetics in nitrogenflushed milk was not statistically different from that in untreated milk except for Lc. lactis ssp. lactis CHCC D2, which showed faster reduction time after nitrogen flushing. This study clarifies the relationship between the redox state in milk and acidification kinetics of the predominant subspecies in DL-starter cultures. This knowledge is important for dairies to ensure optimized, fast, and controlled milk fermentations, leading to greater standardization of dairy products.

Key words: lactic acid bacteria, milk acidification, redox potential, initial oxygen concentration

\section{INTRODUCTION}

Mesophilic starter cultures are used in the production of cheeses and other dairy products due to their ability to acidify milk, their proteolytic activity, and the ability to form aroma compounds. Starter cultures for cheese manufacturing are typically derived from traditional dairy-propagated starters. Among them, the starters used for European continental semi-hard cheeses, such as Gouda, Edam, and the Danish cheese Danbo, are commonly composed of an undefined mixture of non-citrate-fermenting and citrate-fermenting strains of Lactococcus lactis together with Leuconostoc mesenteroides ssp. cremoris.

Growth and activity of DL-starter cultures [cultures containing Lactococcus lactis diacetylactis (D) and Leuconostoc (L) species] and thereby final cheese quality depend strongly on the environmental parameters. One of the essential parameters is the oxidation-reduction (redox) potential $\left(\boldsymbol{E}_{\mathrm{h}}\right)$, which characterizes the ability of a system to accept (reduce) or donate (oxidize) electrons. Positive redox potential values indicate an environment that favors oxidation reactions, whereas negative values refer to a reducing environment (Caldeo and McSweeney, 2012). The values of redox potential in milk vary from +250 to $+350 \mathrm{mV}$ at $25^{\circ} \mathrm{C}$ and natural $\mathrm{pH}$ of 6.6 to 6.7 (Schreyer et al., 2008). Dissolved oxygen is the principal factor in determining $E_{\mathrm{h}}$, because oxygen affects the balance of oxidizing and reducing agents present in milk. Other important factors involve 
the lactate:pyruvate ratio, concentrations of ascorbate, the thiol groups, and metal ions (McSweeney et al., 2010). The effect of the major milk components (fat, lactose, and casein) on $E_{\mathrm{h}}$ was found to be relatively small (Morris, 2000; Schreyer et al., 2008).

The development of $E_{\mathrm{h}}$ throughout cheese making depends on milk quality, cheese technology, and, to a large extent, on the starter culture (Brasca et al., 2007; Caldeo and McSweeney, 2012). Fermentation of residual lactose and consumption of oxygen by lactic acid bacteria ( $\mathbf{L A B}$ ) results in a decrease of redox potential, thereby creating an anaerobic environment in which only obligatory or facultative anaerobic microbes can grow (Beresford et al., 2001; Boucher et al., 2006). On the other hand, $E_{\mathrm{h}}$ affects the metabolic pathways of LAB and production of aroma compounds in cheeses (Martin et al., 2011). It has been reported that oxidative conditions in milk favor the production of aldehydes and the volatile sulfur compounds responsible for fruity and almond aromas, whereas reducing conditions stimulate the production of carboxylic acids, which contribute to ripened-cheese aroma (Kieronczyk et al., 2006).

Effect of initial oxygen on milk fermentation by Lactococcus lactis has been addressed in only a few publications and remains poorly described (Cachon et al., 2002; Brasca et al., 2007; Jeanson et al., 2009; Abraham et al., 2013). To our knowledge, the effect of initial oxygen on milk reduction by Leuconostoc mesenteroides has not been reported to date. The objective of this study was therefore to investigate the effect of dissolved oxygen and thereby initial redox potential on reduction and acidification kinetics of milk fermentation by $L c$. lactis and Leu. mesenteroides strains isolated from a commercial mixed DL-starter culture compared with the starter culture itself. The initial levels of dissolved oxygen in milk were manipulated by flushing milk with either oxygen or nitrogen and compared with untreated milk to study strain diversity and the relationship between reduction and acidification abilities of the strains.

\section{MATERIALS AND METHODS}

\section{Bacterial Strains and Reagents}

An undefined, mixed, commercial DL-starter culture A (Chr. Hansen A/S, Hørsholm, Denmark) and 9 strains of LAB were used in this study (Table 1). Six strains were isolated from the DL-starter culture and previously identified as Lc. lactis ssp. lactis biovar. diacetylactis (strains CHCC D1, CHCC D2 and CHCC D3), Lc. lactis ssp. cremoris (strains $\mathrm{CHCC} \mathrm{O1}$ and $\mathrm{CHCC}$ O2), and Leu. mesenteroides ssp. cremoris (CHCC M1) based on $16 \mathrm{~S}$ DNA sequencing and phenotypic data
Table 1. Lactic acid bacteria (LAB) used in this study

\begin{tabular}{ll}
\hline LAB & ${\text { Strain } \mathrm{ID}^{1}}^{1}$ \\
\hline Lactococcus lactis ssp. lactis biovar. diacetylactis & DSM 4366 \\
& CHCC D1 \\
& CHCC D2 \\
Lactococcus lactis ssp. cremoris & CHCC D3 \\
& DSM 20069 \\
Leuconostoc mesenteroides ssp. cremoris & CHCC O1 \\
& CHCC O2 \\
DL-starter culture & DSM 20346 \\
& CHCC M1 \\
\hline
\end{tabular}

${ }^{1} \mathrm{CHCC}$ strains were isolated from the DL-starter culture A at Chr. Hansen A/S (Hørsholm, Denmark). The DSM strains were from the DSMZ collection (Deutsche Sammlung von Mikroorganismen und Zellkulturen, Braunschweig, Germany).

${ }^{2}$ The DL-starter culture A contained aroma-producing Lc. lactis ssp. lactis biovar. diacetylactis (D) and Leuconostoc mesenteroides ssp. cremoris $(\mathrm{L})$ along with acidifying species Lc. lactis ssp. lactis and Lc. lactis ssp. cremoris.

(data not shown). The type strains Lc. lactis ssp. lactis biovar. diacetylactis DSM $4366^{\mathrm{T}}$, Lc. lactis ssp. cremoris DSM $20069^{\mathrm{T}}$, and Leu. mesenteroides ssp. cremoris


von Mikroorganismen und Zellkulturen, Braunschweig, Germany) were used as references. Strains were stored in M17 medium or de Man, Rogosa, and Sharpe (MRS) broth for Lactococcus spp. or Leuconostoc spp., respectively, supplemented with $20 \%$ (vol/vol) glycerol at $-80^{\circ} \mathrm{C}$. The DL-starter culture was stored as a frozen pellet of exponential-phase culture in milk at $-40^{\circ} \mathrm{C}$. Reagents for the experiments were purchased from Sigma A/S (Brøndby, Denmark) or Becton, Dickinson and Co. (Albertslund, Denmark) unless stated otherwise.

\section{Fermentation Conditions}

Fermentations were performed in full-fat (3.5\%) UHT milk, purchased at a local market in Copenhagen, Denmark, with $0.2 \%$ (wt/vol) tryptone added to facilitate growth of protease-negative strains. The fermenters were blue-capped bottles with a fermentation volume of $700 \mathrm{~mL}$. The bottles had a wide neck and a lid that allowed fittings for 3 sensors. Before inoculation, the milk in fermenters was flushed with either oxygen $\left(\mathrm{O}_{2}\right)$ or nitrogen $\left(\mathrm{N}_{2}\right)$ for $40 \mathrm{~min}$ or not flushed with either gas. Before the experiments, strains were propagated in UHT milk at $30^{\circ} \mathrm{C}$ overnight to about $10^{9} \mathrm{cfu} / \mathrm{mL}$. Overnight cultures of $1 \%$ (vol/vol) were added to UHT milk and incubated for $3 \mathrm{~h}$ at $30^{\circ} \mathrm{C}$ to reach the exponential growth phase. Milk in fermenters was inoculated with pure strains in the exponential phase or with DL-starter culture A as a frozen pellet at a density of $10^{5} \mathrm{cfu} / \mathrm{mL}$. Fermentations were performed at $30^{\circ} \mathrm{C}$ for 
$24 \mathrm{~h}$ with agitation of $250 \mathrm{rpm}$. All fermentations were conducted in at least 3 replicates. Bacterial growth was followed by plating serial dilutions of bacterial cultures in milk on either LM17 agar for Lc. lactis strains or MRS agar for Leu. mesenteroides strains. The cell counts were determined after incubation of LM17 agar plates at $30^{\circ} \mathrm{C}$ for $48 \mathrm{~h}$ and MRS agar plates at $25^{\circ} \mathrm{C}$ and anaerobic conditions for $72 \mathrm{~h}$.

\section{Data Acquisition and Treatment}

Dissolved oxygen $\left(\mathbf{d O}_{2}\right)$ was measured with an optical oxygen sensor (Hamilton Visiferm DO 120, Yokogawa Electric Corp., Amersfoort, the Netherlands). Oxygen sensors were calibrated so that measured values of $100 \% \mathrm{dO}_{2}$ corresponded to the concentration of oxygen in air $(21 \%)$. Redox potential and $\mathrm{pH}$ were monitored with a combined electrode (Hamilton Easyferm Plus $\mathrm{Rx}$ VP 120). Signals from the $\mathrm{pH} /$ redox electrode were converted by a $\mathrm{pH} / \mathrm{ORP}$ converter (PH450G, Yokogawa, Tokyo, Japan) and recorded by DataLogger FX112-4-2 (Yokogawa). The redox potential directly measured $\left(E_{\mathrm{m}}\right)$ with sensors was corrected for $\mathrm{Ag} / \mathrm{AgCl}$ reference electrode $\left(E_{\mathrm{r}}=194 \mathrm{mV}\right)$, such that $E_{\mathrm{h}}=E_{\mathrm{m}}$ $+E_{\mathrm{r}}$ (Abraham et al., 2013). The redox potential was further converted to a standard electrode potential at $\mathrm{pH} 7\left(\boldsymbol{E}_{\mathrm{h} 7}\right)$ as follows: $E_{\mathrm{h} 7}=E_{\mathrm{h}}-\alpha(7-\mathrm{pH})$, where $\alpha$ is a regression factor determined experimentally in milk and equal to $32.7 \pm 0.8$. Data were recorded every 5 min during a 24-h fermentation.

Milk acidifications were followed by measuring $\mathrm{pH}$, $\mathrm{E}_{\mathrm{h} 7}$, and $\mathrm{dO}_{2}$. Derivatives of $\mathrm{pH}$ changes and redox potential were constructed to describe acidification and reduction rates, respectively. Parameters extracted from the acidification rate curves were the maximum acidification rate $\left(\mathbf{V}^{\mathrm{a}}{ }_{\max } ; \mathrm{mV} / \mathrm{min}\right)$ and time of maximum acidification rate $\left(\mathbf{T}_{\text {max }}^{\mathrm{a}} ; \mathrm{h}\right)$. Reduction parameters were the maximum reduction rate $\left(\mathbf{V}^{\mathrm{r}}{ }_{\max } ; \mathrm{mV} /\right.$ min), time of the maximum reduction rate $\left(\mathbf{T}^{\mathrm{r}}{ }_{\text {max }}\right.$; $\mathrm{h}$ ), the minimum redox potential $\left(\mathbf{E}_{\mathrm{h} 7 \text { final }} ; \mathrm{mV}\right)$, and time of reaching $\mathrm{E}_{\mathrm{h} 7 \text { final }}\left(\mathbf{T}_{\text {final }}^{\mathrm{r}} \mathrm{h}\right)$. To compensate for inoculum size, all experimental data were adjusted to fermentation start at acidification rate $\mathrm{V}^{\mathrm{a}}$ max $=0.06$ $\mathrm{mV} / \mathrm{min}$.

\section{Statistical Analysis}

Differences across the strains were evaluated using 2-way ANOVA with Bonferroni's multiple comparisons test using GraphPad Prism software version 6.03 (GraphPad Inc., San Diego, CA). Differences between fermentation parameters determined in flushed milk compared with controls (untreated milk) were assessed by paired 2-tailed Student's $t$-test (Excel 2010; Micro- soft Corp., Redmond, WA). Results with $P$-values $<$ 0.05 were considered significantly different. Principal components analysis (PCA) of the acidification data was performed using the Latentix 2.11 software (Copenhagen, Denmark).

\section{RESULTS}

\section{Initial Levels of Dissolved Oxygen and Redox Potential in Milk}

The initial redox potential in untreated milk was +272 $\mathrm{mV}$ and the dissolved oxygen was $57 \%$ (mean percentage of air saturation in the following). As expected, the levels of $E_{\mathrm{h} 7}$ and $\mathrm{dO}_{2}$ were significantly affected $(P<$ 0.05 ) by milk treatment with gases (Table 2). Flushing with oxygen increased the redox potential to $+319 \mathrm{mV}$ and $\mathrm{dO}_{2}$ to $293 \%$, whereas flushing with $\mathrm{N}_{2}$ reduced the initial $\mathrm{E}_{\mathrm{h} 7}$ to $+231 \mathrm{mV}$ and $\mathrm{dO}_{2}$ to $17 \%$. The initial $\mathrm{pH}$ values between 6.45 and 6.52 were statistically the same at all conditions. The levels of redox potential in milk without inoculation remained stable for at least $12 \mathrm{~h}$ after flushing (results not shown), indicating that there was no leakage in the system.

\section{Effect of Initial Oxygen on Milk Acidification by DL-Starter Culture $A$}

Kinetic curves and parameters of milk acidification by the DL-starter culture A at different levels of initial oxygen are shown in Figure 1 and Table 3. The redox potential in untreated milk was stable or increased slightly for about $2.8 \mathrm{~h}$ after the start of fermentation and decreased rapidly along with oxygen depletion (Figure 1A). A maximum reduction rate $\left(\mathrm{V}^{\mathrm{r}}\right.$ max $)$ of $75 \mathrm{mV} /$ min was achieved at $\mathrm{T}_{\text {max }}^{\mathrm{r}}=2.92 \mathrm{~h}$, concurrently with oxygen consumption (Table 3 ). Afterward, a decrease of $E_{\mathrm{h} 7}$ was shifted to a more gradual slope before reaching the minimum values (Figure 1A). The minimum redox potential $\left(E_{\mathrm{h} 7 \text { final }}=-216 \mathrm{mV}\right)$ was recorded after $5.21 \mathrm{~h}$ of fermentation $\left(\mathrm{T}_{\text {final }}^{\mathrm{r}}\right)$. The $\mathrm{pH}$ in milk decreased after $2 \mathrm{~h}$ of fermentation (Figure 1B)

Table 2. Initial levels of dissolved oxygen $\left(\mathrm{dO}_{2}\right)$, redox potential $\left(E_{\mathrm{h} 7}\right.$; standardized to $\mathrm{pH} 7$ ), and $\mathrm{pH}$ in milk flushed with oxygen or nitrogen and unflushed milk ${ }^{1}$

\begin{tabular}{lrrr}
\hline Treatment & $\mathrm{dO}_{2}(\%)$ & $E_{\mathrm{h} 7}(\mathrm{mV})$ & $\mathrm{pH}$ \\
\hline $\mathrm{O}_{2}$ flushing & $293^{* *} \pm 7$ & $+319^{*} \pm 27$ & $6.49 \pm 0.06$ \\
$\mathrm{~N}_{2}$ flushing & $17^{* *} \pm 3$ & $+231^{*} \pm 45$ & $6.52 \pm 0.04$ \\
No flushing & $57 \pm 6$ & $+272 \pm 51$ & $6.45 \pm 0.05$ \\
\hline
\end{tabular}

${ }^{1}$ Mean values \pm SD were determined from 4 independent repeats. ${ }^{*} P<0.05$; ${ }^{*} P<0.01$ : significant differences between the treatments compared with untreated milk (determined by paired 2-tailed Student's t-test). 
and reached a plateau ( $\mathrm{pH}$ of 4.5$)$ after $8 \mathrm{~h}$ of fermentation. The $\mathrm{pH}$ derivative curves of the culture A displayed 2 maxima of acidification rate (Figure 1B). The lower maximum rate $\left(\mathrm{V}_{\text {max aerob }}^{\mathrm{a}}=0.29 \mathrm{mV} / \mathrm{min}\right)$ was detected before oxygen depletion (aerobic maximum) at time $\mathrm{T}_{\text {max aerob }}^{\mathrm{a}}=3.15 \mathrm{~h}$. The second rate maximum was observed under anaerobic conditions $\left(\mathrm{V}^{\mathrm{a}}\right.$ max anaerob $=$ $0.39 \mathrm{mV} / \mathrm{min}$ and $\mathrm{T}_{\text {max anaerob }}^{\mathrm{a}}=5.18 \mathrm{~h}$ ), just before the redox potential reached its final value.

Kinetic parameters of the DL-starter culture were significantly affected by oxygen flushing compared with the unflushed milk (Table 3). The time of reaching the first acidification maximum $\left(\mathrm{T}^{\mathrm{a}}{ }_{\text {max aerob }}=2.86\right.$ h) was shortened $(P<0.05)$ in milk with high initial oxygen. Concurrently, the rate of anaerobic maximum $\left(\mathrm{V}_{\text {max anaerob }}^{\mathrm{a}}=0.36 \mathrm{mV} / \mathrm{min}\right)$ was significantly decreased $(P<0.05)$ and the time was delayed $(P<$ $0.01)$ by approximately $1 \mathrm{~h}\left(\mathrm{~T}_{\max \text { anaerob }}^{\mathrm{a}}=6.02 \mathrm{~h}\right)$. Furthermore, the decrease of redox potential was slowed by more than $1 \mathrm{~h}$ in oxygen-flushed milk $\left(\mathrm{T}^{\mathrm{r}}{ }_{\max }=4.21 \mathrm{~h}\right.$ and $\mathrm{T}_{\text {final }}^{\mathrm{r}}=6.08 \mathrm{~h}$ ). Kinetic parameters determined for the culture $\mathrm{A}$ in nitrogen-flushed milk (low initial $\mathrm{dO}_{2}$ ) were not statistically different from the untreated milk.

\section{Growth and Acidification Kinetics of Lc. lactis and Leu. mesenteroides Strains in Untreated Milk}

Strains of LAB were grown exponentially in untreated milk during the first $8 \mathrm{~h}$ of fermentation (data not shown). A lag phase was not observed because the inoculum culture was in exponential phase adapted to the fermentation conditions. Strains of Lc. lactis ssp. lactis and Lc. lactis ssp. cremoris reached the stationary phase at a cell density of $8.8 \log _{10} \mathrm{cfu} / \mathrm{mL}$ after approximately $10 \mathrm{~h}$ of fermentation. Leuconostoc mesenteroides ssp. cremoris CHCC 9935 and DSM $20346^{\mathrm{T}}$ grew slower than other strains to $7.5 \log _{10} \mathrm{cfu} / \mathrm{mL}$ after $10 \mathrm{~h}$, followed by a further increase of cell counts to 8.5 $\log _{10} \mathrm{cfu} / \mathrm{mL}$ after $24 \mathrm{~h}$ of fermentation.

Kinetic parameters in untreated milk varied considerably between strains and species (Table 4). Strain CHCC D2 was characterized by the lowest acidification capacity among the Lc. lactis ssp. lactis strains. This strain took longer to reach the maxima of acidification rate $\left(\mathrm{T}_{\text {max aerob }}^{\mathrm{a}}=3.96 \mathrm{~h}\right.$ and $\left.\mathrm{T}_{\text {max anaerob }}^{\mathrm{a}}=6.05 \mathrm{~h}\right)$ compared with the fastest strain, CHCC D3 ( $\mathrm{T}_{\text {max aerob }}^{\mathrm{a}}$ $=2.32 \mathrm{~h}$ and $\mathrm{T}_{\text {max anaerob }}^{\mathrm{a}}=3.97 \mathrm{~h}$ ) and had a lower


pared with $0.41 \mathrm{mV} / \mathrm{min}$ for $\mathrm{CHCC}$ D3). The highest reducing capacity was determined for reference strain DSM $4366^{\mathrm{T}}\left(E_{\mathrm{h} 7 \text { final }}=-217 \mathrm{mV}\right.$ and $\mathrm{V}^{\mathrm{r}}$ max $=36 \mathrm{mV} /$ $\min )$ followed by CHCC D2 ( $E_{\mathrm{h} 7 \text { final }}=-184 \mathrm{mV}$ and $\left.\mathrm{V}_{\text {max }}^{\mathrm{r}}=15 \mathrm{mV} / \mathrm{min}\right)$. Strains CHCC D3 and CHCC D1
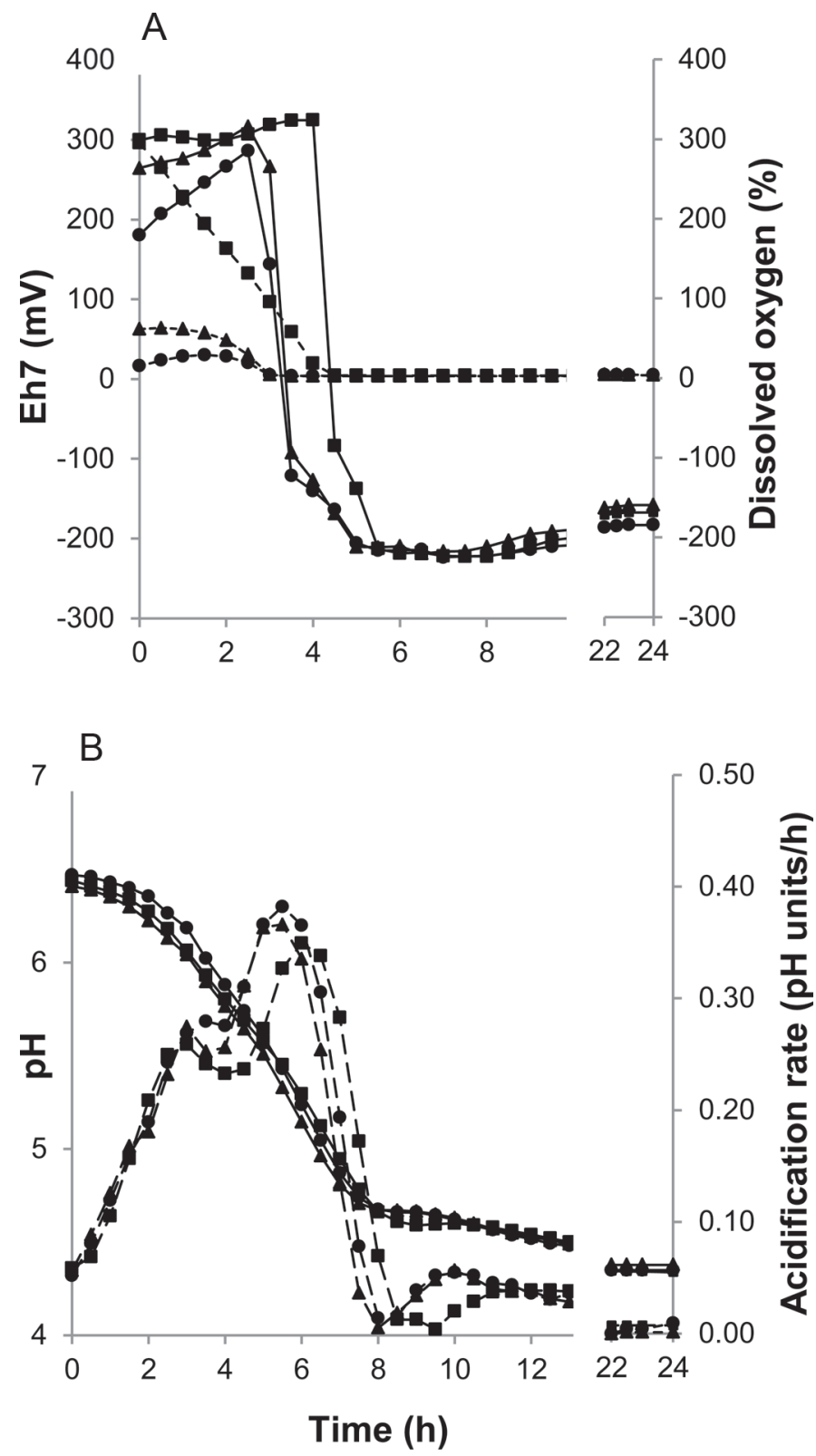

Figure 1. Kinetic curves of milk acidification and reduction by the DL-starter culture A. (A) Redox potential ( $E_{\mathrm{h} 7}, \mathrm{mV}$; solid curves) and dissolved oxygen (\%; dashed curves); (B) pH curves (solid curves) and acidification rate, $\mathrm{pH}$ units/h (dashed curves). Milk fermentation was performed at high (solid squares), low (solid circles), and normal (solid triangles) initial levels of dissolved oxygen.

were unable to decrease the redox potential to negative values $\left(E_{\mathrm{h} 7 \text { final }}=5\right.$ to $\left.11 \mathrm{mV}\right)$.

Fermentation parameters of Lc. lactis ssp. cremoris strains were statistically the same except for DSM $20069^{\mathrm{T}}$, which exhibited a lower rate and shorter time of reduction $\left(\mathrm{V}_{\max }^{\mathrm{r}}=17 \mathrm{mV} / \min\right.$ and $\left.\mathrm{T}_{\max }^{\mathrm{r}}=2.41 \mathrm{~h}\right)$ than strains $\mathrm{CHCC}$ O1 $\left(\mathrm{V}^{\mathrm{r}}\right.$ max $=25 \mathrm{mV} / \mathrm{min}, \mathrm{T}^{\mathrm{r}}{ }_{\max }=$ $4.50 \mathrm{~h})$ and CHCC O2 $\left(\mathrm{V}^{\mathrm{r}}{ }_{\max }=32 \mathrm{mV} / \mathrm{min}, \mathrm{T}^{\mathrm{r}}{ }_{\max }=\right.$ 
Table 3. Kinetic parameters of milk acidification and reduction by the DL-starter culture at high, low, and normal initial levels of dissolved oxygen $\left(\mathrm{dO}_{2}\right)^{1}$

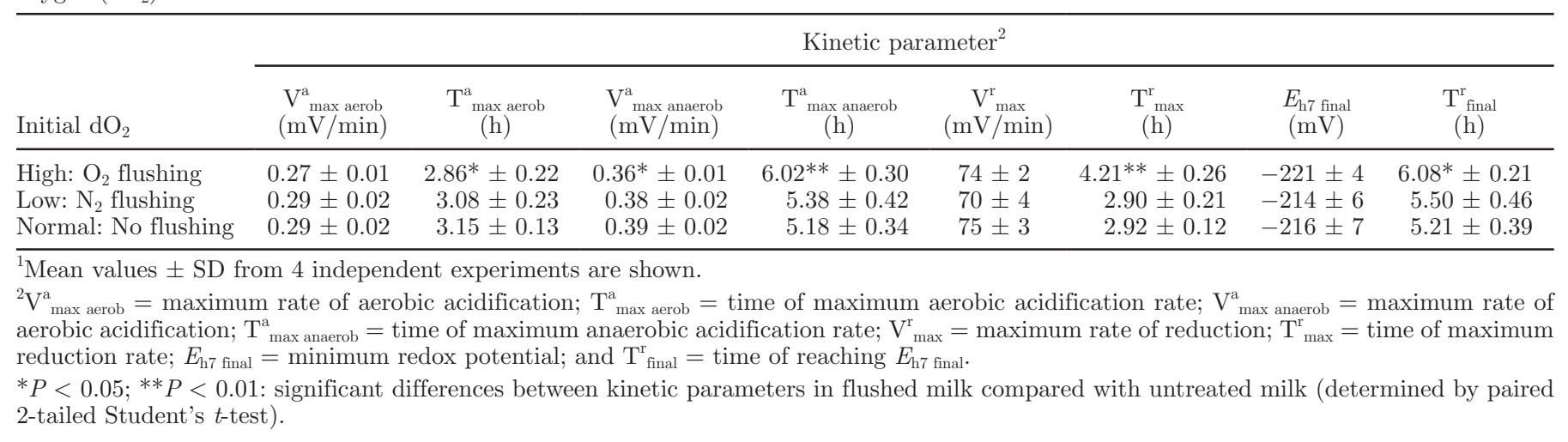

$3.81 \mathrm{~h})$. All Lc. lactis ssp. cremoris strains had a good reduction capacity, reaching the minimum redox potential ( $E_{\mathrm{h} 7 \text { final }}$ to $-210 \mathrm{mV}$ ) after 5 or $6 \mathrm{~h}$ of fermentation. Similar results were found for the Lc. lactis ssp. lactis strains, in which acidification curves of Lc. lactis ssp. cremoris displayed 2 rate maxima: $\mathrm{V}^{\mathrm{a}}$ max aerob of 0.25 to $0.26 \mathrm{mV} / \mathrm{min}$ and $\mathrm{V}^{\mathrm{a}}$ max anaerob of 0.39 to $0.40 \mathrm{mV} / \mathrm{min}$.

The acidification pattern of Leu. mesenteroides ssp. cremoris CHCC M1 and DSM 20346 ${ }^{\mathrm{T}}$ differed from that of the other tested LAB. Three maxima of acidification rate were observed for strain CHCC M1, including a minor rate maximum $\left(\mathrm{V}^{\mathrm{a}}\right.$ max aerob $\left.=0.15 \mathrm{mV} / \mathrm{min}\right)$ under aerobic conditions and 2 clear peaks $\left(\mathrm{V}^{\mathrm{a}}\right.$ max anaerob of 0.32 and $0.49 \mathrm{mV} / \mathrm{min}$ ) after oxygen consumption. Strain DSM $20346^{\mathrm{T}}$ displayed a single-rate maximum at anaerobic conditions $\left(\mathrm{V}^{\mathrm{a}}\right.$ max anaerob $\left.=0.44 \mathrm{mV} / \mathrm{min}\right)$. In addition, strain CHCC M1 decreased redox potential at a faster rate than the type strain DSM20346 ${ }^{\mathrm{T}}\left(\mathrm{V}^{\mathrm{r}}\right.$ max of 72 vs. $34 \mathrm{mV} / \mathrm{min}$, respectively) and the other $L c$. lactis strains tested.

Diversity between strains with regard to their acidification and reduction kinetics was investigated by PCA (Figure 2). Variance between bacterial strains (PCA loadings) could be described by the 2 principal components (PC), accounting for 41\% (PC1) and 30\% (PC2) of the total variance. Bacterial strains formed several groups in the PCA loading plot according to similarity of their kinetics (Figure 2A). Strains Lc. lactis ssp. cremoris $\mathrm{CHCC} \mathrm{O} 1$ and $\mathrm{CHCC} \mathrm{O} 2$ were grouped together with Lc. lactis ssp. lactis strains CHCC D2 and DSM $4366^{\mathrm{T}}$. This group was separated along PC1 from another group consisting of Lc. lactis ssp. lactis $\mathrm{CHCC}$ D3 and CHCC D1. Variance between these groups was associated with higher scores of $\mathrm{T}^{\mathrm{a}}$ anaerob and $\mathrm{T}^{\mathrm{r}}{ }_{\max }$ in the first group versus higher scores of $E_{\mathrm{h} 7 \text { final }}$ in the second group (Figure 2B). Grouping of the starter culture A and CHCC M1 was related to their similarity in maximum reduction rate $\left(\mathrm{V}^{\mathrm{r}}{ }_{\max }\right)$. The type strains
DSM $20069^{\mathrm{T}}$ and DSM $20346^{\mathrm{T}}$ were separated from each other along PC2 and were not grouped with the other strains, emphasizing differences in their fermentation performance.

\section{Effect of Initial Oxygen on Acidification Kinetics of Lc. lactis and Leu. mesenteroides}

Kinetic parameters of milk acidification and development of redox potential were significantly affected by oxygen flushing (Table 5). Generally, $\mathrm{T}_{\max }^{\mathrm{r}}$ and $\mathrm{T}_{\text {final }}^{\mathrm{r}}$ were significantly extended at high initial $\mathrm{dO}_{2}$ compared with at normal oxygen levels. Additionally, $\mathrm{V}_{\text {max }}^{\mathrm{r}}$ of strains Lc. lactis CHCC O2, DSM $20069^{\mathrm{T}}$, and DSM $4366^{\mathrm{T}}$ was increased $(P<0.05)$. Lactococcus lactis ssp. lactis CHCC D2 was highly responsive to initial oxygen content $\left(\mathrm{T}^{\mathrm{r}}{ }_{\max }=5.46 \mathrm{~h}\right.$ and $\mathrm{T}_{\text {final }}^{\mathrm{r}}=7.46 \mathrm{~h}$ at high $\mathrm{dO}_{2}$ vs. $3.13 \mathrm{~h}$ and $5.75 \mathrm{~h}$, respectively, at normal $\mathrm{dO}_{2}$ ). The longest delay of reduction activity among Lc. lactis ssp. cremoris strains was recorded for CHCC O2 $\left(\mathrm{T}^{\mathrm{r}}{ }_{\max }=\right.$ $7.55 \mathrm{~h}$ and $\mathrm{T}_{\text {final }}^{\mathrm{r}}=8.50 \mathrm{~h}$ in oxygenated milk vs. $3.81 \mathrm{~h}$ and $5.92 \mathrm{~h}$, respectively, in unflushed milk). Similarly, a decrease in redox potential by Leu. mesenteroides strains CHCC M1 and DSM $20346^{\mathrm{T}}$ was postponed by about $1 \mathrm{~h}$ by oxygen flushing. Faster reduction rates $(P<0.05)$ in response to high $\mathrm{dO}_{2}$ were recorded for Lc. lactis ssp. cremoris $\mathrm{CHCC} \mathrm{O} 2$ and for the reference strains DSM $20069^{\mathrm{T}}$, DSM4366 ${ }^{\mathrm{T}}$, and DSM $20346^{\mathrm{T}}$. The values of $E_{\mathrm{h} 7 \text { final }}$ for individual strains were not significantly altered by flushing. Oxygen treatment had a negative effect on the acidification capacity of Lc. lactis strains (CHCC O1, CHCC O2, and DSM 4366 ${ }^{\mathrm{T}}$ ) and Leu. mesenteroides ssp. cremoris CHCC M1 by decreas-

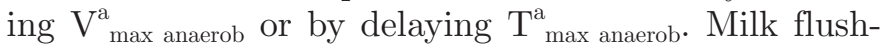
ing with $\mathrm{N}_{2}$ had no significant effect on reduction and acidification parameters of lactic acid bacteria except for Lc. lactis ssp. lactis CHCC D2, which demonstrated a further decrease in reduction time at low initial $\mathrm{dO}_{2}$ 
Table 4. Kinetic parameters of milk acidification and reduction by Lactococcus lactis ssp. lactis, Lc. lactis ssp. cremoris, and Leuconostoc mesenteroides ssp. cremoris at normal initial levels of oxygen

\begin{tabular}{|c|c|c|c|c|c|c|c|c|}
\hline \multirow[b]{2}{*}{ Strain } & \multicolumn{8}{|c|}{ Kinetic parameter ${ }^{2}$} \\
\hline & $\begin{array}{l}\mathrm{V}_{\max }^{\mathrm{a}} \text { aerob } \\
(\mathrm{mV} / \mathrm{min})\end{array}$ & $\begin{array}{l}\mathrm{T}_{\max \text { aerob }}^{\mathrm{a}} \\
(\mathrm{h})\end{array}$ & $\begin{array}{l}\mathrm{V}^{\mathrm{a}}{ }_{\max \text { anaerob }} \\
(\mathrm{mV} / \mathrm{min})\end{array}$ & $\begin{array}{l}\mathrm{T}_{\text {max anaerob }}^{\mathrm{a}} \\
\quad(\mathrm{h})\end{array}$ & $\begin{array}{c}\mathrm{V}_{\max }^{\mathrm{r}} \\
(\mathrm{mV} / \min )\end{array}$ & $\begin{array}{c}\mathrm{T}_{\max }^{\mathrm{r}} \\
(\mathrm{h})\end{array}$ & $\begin{array}{l}E_{\mathrm{h} 7 \text { final }} \\
(\mathrm{mV})\end{array}$ & $\begin{array}{l}\mathrm{T}_{\text {final }}^{\mathrm{r}} \\
(\mathrm{h})\end{array}$ \\
\hline \multicolumn{9}{|c|}{ Lc. lactis ssp. lactis biovar. diacetylactis } \\
\hline CHCC D1 & $0.26^{\mathrm{b}} \pm 0.03$ & $2.36^{\mathrm{b}} \pm 0.27$ & $0.33^{\mathrm{ab}} \pm 0.05$ & $4.42^{\mathrm{ab}} \pm 0.16$ & $6^{\mathrm{a}} \pm 2$ & $2.56^{\mathrm{a}} \pm 0.56$ & $11^{\mathrm{a}} \pm 17$ & $6.30^{\mathrm{bc}} \pm 0.79$ \\
\hline CHCC D2 & $0.25^{\mathrm{b}} \pm 0.02$ & $3.96^{\mathrm{c}} \pm 0.28$ & $0.27^{\mathrm{a}} \pm 0.06$ & $6.05^{\mathrm{c}} \pm 0.53$ & $15^{\mathrm{b}} \pm 3$ & $3.13^{\text {ab }} \pm 0.06$ & $-184^{\mathrm{b}} \pm 5$ & $5.75^{\mathrm{b}} \pm 0.35$ \\
\hline CHCC D3 & $0.26^{\mathrm{b}} \pm 0.02$ & $2.32^{\mathrm{b}} \pm 0.28$ & $0.41^{\mathrm{b}} \pm 0.02$ & $3.97^{\mathrm{a}} \pm 0.33$ & $5^{\mathrm{a}} \pm 2$ & $2.47^{\mathrm{a}} \pm 0.16$ & $5^{\mathrm{a}} \pm 3$ & $6.80^{\mathrm{c}} \pm 0.57$ \\
\hline DSM $4366^{\mathrm{T}}$ & $0.26^{\mathrm{b}} \pm 0.02$ & $2.30^{\mathrm{b}} \pm 0.18$ & $0.35^{\mathrm{ab}} \pm 0.02$ & $5.25^{\mathrm{b}} \pm 0.11$ & $36^{\mathrm{d}} \pm 3$ & $4.38^{\mathrm{b}} \pm 0.16$ & $-217^{\mathrm{c}} \pm 3$ & $6.84^{\mathrm{c}} \pm 0.12$ \\
\hline \multicolumn{9}{|c|}{ Lc. lactis ssp. cremoris } \\
\hline $\mathrm{CHCC}$ O1 & $0.26^{\mathrm{b}} \pm 0.04$ & $2.65^{\mathrm{b}} \pm 0.10$ & $0.40^{\mathrm{ab}} \pm 0.05$ & $5.42^{\mathrm{bc}} \pm 0.49$ & $25^{\mathrm{c}} \pm 1$ & $4.50^{\mathrm{b}} \pm 0.86$ & $-204^{\mathrm{bc}} \pm 13$ & $6.19^{\mathrm{bc}} \pm 0.55$ \\
\hline $\mathrm{CHCC} \mathrm{O} 2$ & $0.25^{\mathrm{b}} \pm 0.02$ & $2.67^{\mathrm{b}} \pm 0.38$ & $0.40^{\mathrm{ab}} \pm 0.04$ & $5.11^{\mathrm{ab}} \pm 0.72$ & $32^{\mathrm{cd}} \pm 6$ & $3.81^{\mathrm{ab}} \pm 0.90$ & $-201^{b c} \pm 8$ & $5.92^{\mathrm{bc}} \pm 1.17$ \\
\hline DSM $20069^{\mathrm{T}}$ & $0.26^{\mathrm{b}} \pm 0.02$ & $2.67^{\mathrm{b}} \pm 0.25$ & $0.39^{\mathrm{ab}} \pm 0.05$ & $4.23^{\mathrm{ab}} \pm 0.57$ & $17^{\mathrm{b}} \pm 3$ & $2.41^{\mathrm{a}} \pm 0.43$ & $-210^{\mathrm{bc}} \pm 6$ & $6.20^{\mathrm{bc}} \pm 0.52$ \\
\hline \multicolumn{9}{|c|}{ Leu. mesenteroides ssp. cremoris } \\
\hline CHCC M1 & $0.15^{\mathrm{a}} \pm 0.02$ & $1.67^{\mathrm{a}} \pm 0.02$ & $\begin{array}{r}0.32^{\mathrm{ab}} \pm 0.02 \\
0.49^{\mathrm{c}} \pm 0.02\end{array}$ & $\begin{array}{r}4.25^{\mathrm{ab}} \pm 0.12 \\
5.92^{\mathrm{c}} \pm 0.12\end{array}$ & $72^{\mathrm{e}} \pm 2$ & $2.59^{\mathrm{a}} \pm 0.12$ & $-223^{\mathrm{c}} \pm 7$ & $5.79^{\mathrm{b}} \pm 0.41$ \\
\hline DSM $20346^{\mathrm{T}}$ & $\mathrm{ND}^{3}$ & ND & $0.44^{\mathrm{bc}} \pm 0.03$ & $4.08^{\mathrm{ab}} \pm 0.32$ & $34^{\mathrm{cd}} \pm 2$ & $2.48^{\mathrm{a}} \pm 0.54$ & $-208^{\mathrm{bc}} \pm 6$ & $4.21^{\mathrm{a}} \pm 0.27$ \\
\hline
\end{tabular}

${ }^{a}{ }^{-}$Different superscripts within a column indicate significantly different values $(P<0.05)$ as determined by two-way ANOVA with a use of Bonferroni's multiple comparisons test. ${ }^{1}$ Mean values \pm SD obtained in unflushed milk from at least 3 biological repeats are shown.

${ }^{2} \mathrm{~V}^{\mathrm{a}}$ max aerob $=$ maximum rate of aerobic acidification; $\mathrm{T}_{\text {max aerob }}^{\mathrm{a}}=$ time of maximum aerobic acidification rate; $\mathrm{V}_{\text {max anaerob }}^{\mathrm{a}}=$ maximum rate of aerobic acidification; $\mathrm{T}_{\text {max anaerob }}^{\mathrm{a}}=$ time of maximum anaerobic acidification rate; $\mathrm{V}^{\mathrm{r}}{ }_{\max }=$ maximum rate of reduction; $\mathrm{T}_{\text {max }}^{\mathrm{r}}=$ time of maximum reduction rate; $E_{\mathrm{h} 7 \text { final }}=$ minimum redox potential; and $\mathrm{T}^{\mathrm{r}}{ }_{\text {final }}=$ time of reaching $E_{\mathrm{h} 7 \text { final }}$.

$\stackrel{\text { Oㄹ. }}{3} \mathrm{ND}=$ not detected. 
PCA Scores and Loadings
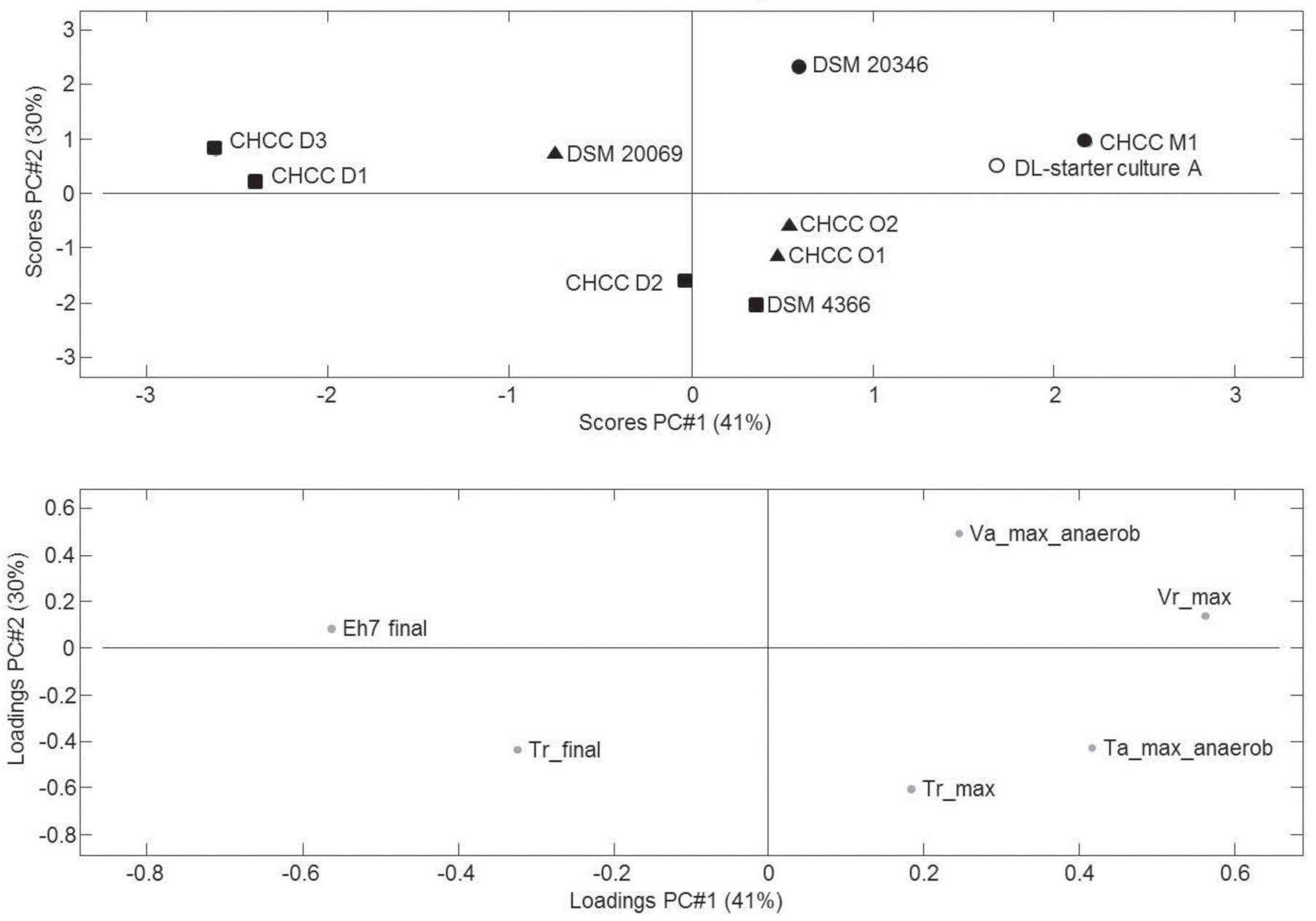

Figure 2. Principal component analysis (PCA) of milk acidification and reduction kinetics. (top) PCA scores: Lactococcus lactis ssp. lactis biovar. diacetylactis CHCC D1, CHCC D2, CHCC D3, and DSM $4366^{\mathrm{T}}$ (solid squares); Lc. lactis ssp. cremoris CHCC O1, CHCC O2, and DSM $20069^{\mathrm{T}}$ (solid triangles); Leuconostoc mesenteroides ssp. cremoris CHCC M1 and DSM20346 $^{\mathrm{T}}$ (solid circles); and the DL-starter culture A (open circle). (bottom) PCA loadings: kinetic parameters at normal oxygen levels, including rate and time of acidification maxima after oxygen depletion $\left(\mathrm{V}_{\mathrm{a} \text { max anaerob }}\right.$ and $\left.\mathrm{T}_{\mathrm{a}-\max \text { anaerob }}\right)$, maximum reduction rate and time $\left(\mathrm{V}_{\mathrm{r} \text { max }}\right.$ and $\left.\mathrm{T}_{\mathrm{r} \max }\right)$ and time $\left(\mathrm{T}_{\mathrm{r} \text { final }}\right)$ of reaching minimum redox potential $\left(\mathrm{E}_{\mathrm{h} \text { f final }}\right)$. Parameters $\mathrm{V}^{\mathrm{a}}$ max aerob and $\mathrm{T}_{\text {max aerob }}^{\mathrm{a}}$ were not included because of missing values (strain DSM $20346^{\mathrm{T}}$ ).

compared with untreated milk (Supplementary Table S1; http://dx.doi.org/10.3168/jds.2014-8971).

Reduction and acidification curves of the most responsive strains of each species of tested LAB (i.e., CHCC D2, CHCC O2, and CHCC M1) as affected by initial oxygen are presented in Figure 3. Similar curves for the other tested bacteria are shown in the Supplementary Figures S1 and S2 (http://dx.doi.org/10.3168/ jds.2014-8971). Typically, shifts of the redox potential curves $\left(E_{\mathrm{h} 7}\right)$ to longer times were observed in oxygenated milk (Figure $3 \mathrm{~A}$ ) compared with untreated and $\mathrm{N}_{2}$-flushed milk (Figure 3B and 3C). The first (aerobic) rate maxima in the $\mathrm{pH}$ curves were commonly displayed as clear peaks at high initial oxygen and looked more like a shoulder at decreased $\mathrm{dO}_{2}$. Bacterial growth and the final $\mathrm{pH}$ values were not significantly affected by milk flushing (data not shown).

\section{DISCUSSION}

In this study, we investigated the effect of initial oxygen levels on kinetics of milk acidification by unidentified DL-starter culture A and strains of Lc. lactis and Leu. mesenteroides isolated from this culture. Milk treatment with oxygen and nitrogen was efficient in manipulating the initial $\mathrm{dO}_{2}$ concentration by several fold. The levels of $E_{h 7}$ were, however, modified to a lesser extent than $\mathrm{dO}_{2}$ and remained positive after nitrogen treatment in accordance with previous reports on milk flushing (Bolduc et al., 2006; Jeanson et al., 2009; Mar- 
Table 5. Kinetic parameters of milk acidification and reduction by Lactococcus lactis ssp. lactis, Lc. lactis ssp. cremoris, and Leuconostoc mesenteroides ssp. cremoris at high initial levels of oxygen

\begin{tabular}{|c|c|c|c|c|c|c|c|c|}
\hline \multirow[b]{2}{*}{ Strain } & \multicolumn{8}{|c|}{ Kinetic parameter $^{2}$} \\
\hline & $\begin{array}{l}\mathrm{V}^{\mathrm{a}}{ }_{\max \text { aerob }} \\
(\mathrm{mV} / \mathrm{min})\end{array}$ & $\begin{array}{l}\mathrm{T}_{\max \text { aerob }}^{\mathrm{a}}(\mathrm{h}) \\
\end{array}$ & $\begin{array}{l}\mathrm{V}^{\mathrm{a}} \max \text { anaerob } \\
(\mathrm{mV} / \mathrm{min})\end{array}$ & $\begin{array}{c}\mathrm{T}_{\text {max anaerob }}^{\mathrm{a}}(\mathrm{h}) \\
\end{array}$ & $\begin{array}{c}\mathrm{V}_{\max }^{\mathrm{r}} \\
(\mathrm{mV} / \mathrm{min})\end{array}$ & $\begin{array}{c}\mathrm{T}_{\max }^{\mathrm{r}} \\
(\mathrm{h})\end{array}$ & $\begin{array}{l}E_{\mathrm{h} 7 \text { final }} \\
(\mathrm{mV})\end{array}$ & $\begin{array}{c}\mathrm{T}_{\text {final }}^{\mathrm{r}} \\
(\mathrm{h})\end{array}$ \\
\hline \multicolumn{9}{|c|}{ Lc. lactis ssp. lactis biovar. diacetylactis } \\
\hline CHCC D1 & $0.27 \pm 0.02$ & $2.25 \pm 0.02$ & $0.38 \pm 0.02$ & $3.97 \pm 0.13$ & $9 \pm 4$ & $3.14^{*} \pm 0.21$ & $6 \pm 6$ & $6.36 \pm 0.34$ \\
\hline CHCC D2 & $0.19 \pm 0.05$ & $2.75^{*} \pm 0.24$ & $0.29 \pm 0.01$ & $6.30 \pm 0.42$ & $13 \pm 8$ & $5.46^{*} \pm 0.53$ & $-180 \pm 3$ & $7.46^{*} \pm 0.06$ \\
\hline CHCC D3 & $0.27 \pm 0.01$ & $2.25 \pm 0.02$ & $0.40 \pm 0.04$ & $3.96 \pm 0.06$ & $6 \pm 2$ & $2.93^{*} \pm 0.02$ & $12 \pm 13$ & $6.13 \pm 0.42$ \\
\hline DSM $4366^{\mathrm{T}}$ & $0.25 \pm 0.03$ & $2.25 \pm 0.11$ & $0.31 \pm 0.03$ & $5.93^{*} \pm 0.04$ & $41^{*} \pm 2$ & $5.00 \pm 0.13$ & $-215 \pm 2$ & $7.45^{*} \pm 0.17$ \\
\hline \multicolumn{9}{|c|}{ Lc. lactis ssp. cremoris } \\
\hline $\mathrm{CHCC} \mathrm{O1}$ & $0.27 \pm 0.06$ & $2.40^{*} \pm 0.11$ & $0.25^{*} \pm 0.06$ & $5.88^{*} \pm 0.42$ & $27 \pm 3$ & $7.13^{*} \pm 1.48$ & $-184 \pm 24$ & $7.92^{*} \pm 1.18$ \\
\hline $\mathrm{CHCC} \mathrm{O} 2$ & $0.30 \pm 0.02$ & $2.97 \pm 0.13$ & $0.21 * \pm 0.02$ & $7.61^{*} \pm 0.60$ & $46^{*} \pm 4$ & $7.55^{*} \pm 0.25$ & $-189 \pm 14$ & $8.50^{*} \pm 0.63$ \\
\hline DSM $20069^{\mathrm{T}}$ & $0.27 \pm 0.03$ & $2.75 \pm 0.29$ & $0.40 \pm 0.06$ & $4.61 \pm 0.67$ & $29^{*} \pm 6$ & $3.31^{*} \pm 0.60$ & $-210 \pm 8$ & $6.05 \pm 0.88$ \\
\hline \multicolumn{9}{|c|}{ Leu. mesenteroides ssp. cremoris } \\
\hline CHCC M1 & $0.22^{*} \pm 0.03$ & $2.00 \pm 0.11$ & $\begin{array}{l}0.29 \pm 0.01 \\
0.46 \pm 0.02\end{array}$ & $\begin{array}{l}4.88^{*} \pm 0.06 \\
6.46^{*} \pm 0.07\end{array}$ & $71 \pm 1$ & $3.34^{*} \pm 0.23$ & $-226 \pm 5$ & $6.38^{*} \pm 0.18$ \\
\hline DSM $20346^{\mathrm{T}}$ & $\mathrm{ND}^{3}$ & ND & $0.47 \pm 0.04$ & $4.19 \pm 0.27$ & $43^{*} \pm 7$ & $3.75^{*} \pm 0.15$ & $-201 \pm 5$ & $4.88^{*} \pm 0.32$ \\
\hline
\end{tabular}

${ }^{1}$ Mean values \pm SD from at least 3 independent experiments are shown.

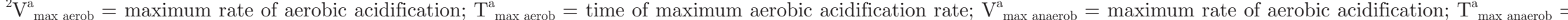
time of maximum anaerobic acidification rate; $\mathrm{V}^{\mathrm{r}}{ }_{\max }=$ maximum rate of reduction; $\mathrm{T}^{\mathrm{r}}{ }_{\max }=$ time of maximum reduction rate; $E_{\mathrm{h} 7 \text { final }}=$ minimum redox potential; and $\mathrm{T}_{\text {final }}^{\mathrm{r}}=$ time ¿ of reaching $E_{\mathrm{h} 7 \text { final }}$

$\stackrel{\check{O}_{3}}{{ }^{3}} \mathrm{ND}=$ not detected.

Oㄹ $* P<0.05$ : significant differences between kinetic parameters at high initial dissolved $\mathrm{O}_{2}$ compared with the normal levels (determined by paired 2-tailed Student's $t$-test). 
A



B
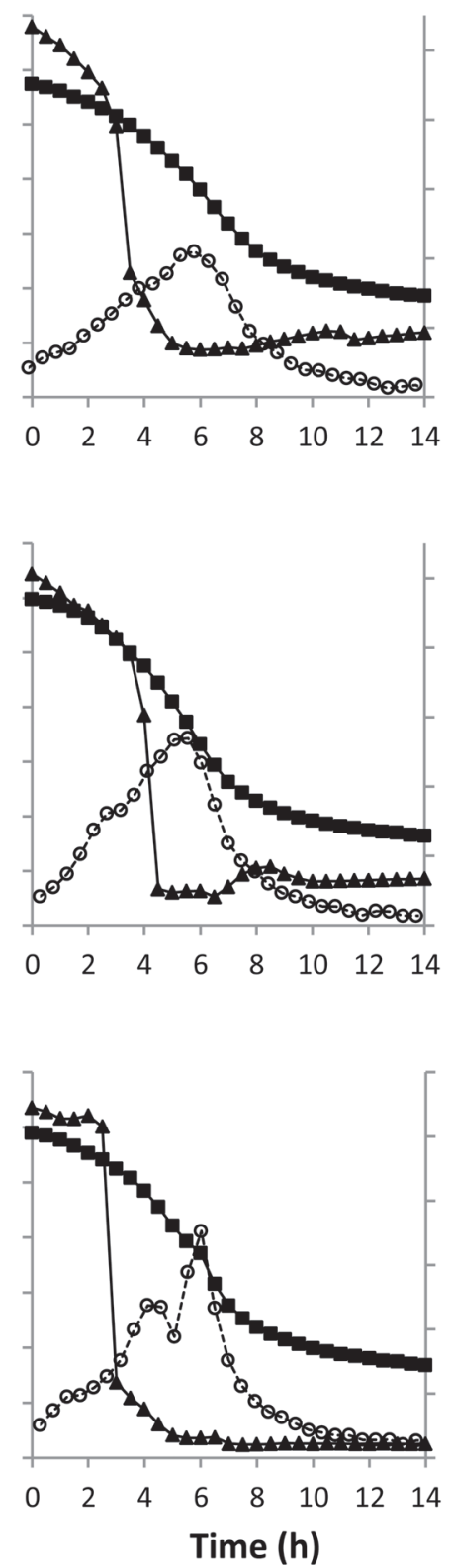

$\mathrm{C}$


Figure 3. Typical kinetic curves of redox potential ( $\mathrm{E}_{\mathrm{h} 7}$; solid triangles), pH (solid squares), and acidification rate (Va; open circles) obtained for Lactococcus lactis ssp. lactis CHCC D2, Lc. lactis ssp. cremoris CHCC O2, and Leuconostoc mesenteroides ssp. cremoris CHCC M1 at high (A), normal (B), and low (C) initial oxygen levels in milk.

tin et al., 2009). Independently of initial conditions, kinetics of milk reduction were correlated with dissolved oxygen, because redox potential decreased rapidly and simultaneously with oxygen depletion. The decrease of $E_{\mathrm{h} 7}$ continued at a slower rate under anaerobic conditions, indicating involvement of biological factors such as microbial activity in the reduction process.

We observed high variation between species and subspecies, and between the strains of the same subspecies in acidification and reduction parameters determined in untreated milk. Two of the Lc. lactis ssp. lactis strains (CHCC D1 and CHCC D3) were unable to decrease $E_{\mathrm{h} 7}$ to negative values after oxygen depletion. At the same time, acidification power of these strains was the same or higher than of the other tested Lc. lactis strains. The inability to decrease the redox potential has been reported previously for Streptococcus thermophilus and Lc. lactis ssp. cremoris (Cachon et al., 2002; Brasca et 
al., 2007). Furthermore, it has been shown that reduction failure in Lc. lactis was due to inactivation of the noxE gene, which encodes NADH oxidase, an enzyme responsible for the rapid removal of oxygen from milk at start of fermentation (Tachon et al., 2010). This mechanism is unlikely to explain reduction failure by CHCC D1 and CHCC D3 in this study, because oxygen was successfully consumed by these strains at a high rate and at a time similar to the reducing strain $\mathrm{CHCC}$ D2. A complementary mechanism, suggested by the same authors, involved the genes nox $A B$ and men $C$, which encode the components of the electron transport chain (ETC; Tachon et al., 2010). The functional part of the ETC is composed of membrane-associated menaquinone, production of which varies between lactic acid bacteria (Brooijmans et al., 2007; Rezaïki et al., 2008; Tachon et al., 2009). The ETC is required for reduction when oxygen concentration reaches zero or under anaerobic conditions; thus, inactivation of ETC might explain the poor reduction activity of the strains in this study.

A characteristic feature of milk acidification by the DL-starter culture A and Lc. lactic strains was the diauxic pattern of the $\mathrm{pH}$ rate curves displayed in a strain-dependent manner. A similar pattern of acidification rate was reported for Lc. lactis strains at high initial oxygen conditions (Jeanson et al., 2009). In the current study, the first acidification rate maximum in untreated milk was observed mostly during the exponential growth phase at aerobic conditions and high $\mathrm{pH}$ $(>6.0)$. A larger maximum of acidification rate occurred after oxygen depletion at low $\mathrm{pH}$ (5.0 to 5.5) concurrently with the transition from the exponential to the stationary growth phase. Shifts in acidification rate are commonly related to alterations in metabolic pathways because of bacterial adaptation to the changes in $\mathrm{dO}_{2}$, $\mathrm{pH}$, and nutrient pool during fermentation. Lactic acid bacteria metabolize lactose by homofermentation of pyruvate to lactate and by mixed acid fermentation with production of acetate, formate, and ethanol (Kowalczyk and Bardowski, 2007). Some strains of Lc. lactis are able to metabolize citrate with production of lactate and mixed acids (diacetyl, acetoin, and butandiol; Magni et al., 1999). Evidence suggests that high oxygen contributes to induction of oxygen-consuming enzymes, including NADH oxidase, pyruvate dehydrogenase, and $\alpha$-acetolactate synthase, whereas lactate dehydrogenase is inhibited (Neves et al., 2002). Consequently, production of lactate is diminished, while mixed acid/flavor fermentation (acetate, acetoin, and diacetyl) is favored. Moreover, pyruvate formate lyase is fully inactivated at aerobic conditions because of its extreme sensitivity to oxygen, and formate is not produced. Diauxic behavior observed for the $\mathrm{pH}$ curves in this study prob- ably reflect redirection of sugar catabolism after oxygen consumption toward homolactic fermentation in detriment of acetate. Under anaerobic conditions, pyruvate dehydrogenase is strongly inhibited by the high NADH concentration (Neves et al., 2005). Alternatively, pyruvate might be converted at anaerobic conditions to formate and ethanol due to relief of pyruvate-formate lyase inhibition and to butandiol (Cocaign-Bousquet et al., 2002).

Acidification pattern of Leu. mesenteroides CHCC M1 in untreated milk differed from that of the other strains by showing 2 anaerobic rate maxima. Leuconostoc spp. are able to catabolize lactose by heterofermentative pathways and utilize citrate, leading mainly to formation of acetate and lactate (Starrenburg and $\mathrm{Hu}-$ genholtz, 1991). The diauxic character of CHCC 9935 acidification curves might be associated with metabolic shifts in heterolactic and citrolactic fermentation. Shifts in lactose-citrate co-metabolism have previously been demonstrated for Leuconostoc oenos, in which acetoin production was favored at $\mathrm{pH}<5$, whereas lactate and acetate were increased at higher $\mathrm{pH}$ values (Ramos et al., 1995). It was assumed that citrolactic fermentation contributed to the growth rate of Leu. mesenteroides under acidic conditions because it resulted in energy gain by synthesis of extra moles of ATP and maintenance of intracellular $\mathrm{pH}$ by proton consumption in the cytoplasm (Marty-Teysset et al., 1996). Supporting this assumption, we observed continued growth of Leu. mesenteroides CHCC M1 and DSM $20346^{\mathrm{T}}$ at $\mathrm{pH}<5.5$ in contrast to the Lc. lactis strains, which remained in stationary growth phase under the same conditions (data not shown).

The maximum rate of acidification of untreated milk by reducing strains in this study was recorded close to the time of the final $E_{\mathrm{h} 7}$, whereas in case of the nonreducing strains (CHCC D1 and CHCC D3), milk acidification preceded the minimum redox potential by about $2 \mathrm{~h}$. These results support the previous findings that demonstrated a link between milk acidification and reduction by LAB (Cachon et al., 2002).

High oxygen is known to be toxic for bacteria, negatively affecting their growth (Nordkvist et al., 2003). However, lactic acid bacteria are also air-tolerant because they can use oxygen as an electron acceptor and convert it to water (Neves et al., 2005). In this study, we did not observe any effect of milk flushing on bacterial growth (data not shown). Similar conclusions regarding Lc. lactis growth in the presence of oxygen have been reached previously (Jeanson et al., 2009). The same authors assumed that upregulation of NADH oxidase activity at aerobic conditions might be efficient enough to compensate for the negative effects of oxygen on bacterial growth (Jeanson et al., 2009). 
Milk flushing with oxygen had a significant effect on acidification kinetics of all tested bacteria in this study. A decrease in redox potential was delayed under high initial oxygen probably because of the longer time needed for oxygen consumption. Similar tendencies were observed during fermentation of oxygenated skim milk by Lc. lactis (Jeanson et al., 2009). The reduction rate of several strains in this study $(\mathrm{CHCC} \mathrm{O} 2, \mathrm{DSM}$ $4366^{\mathrm{T}}$, DSM $20069^{\mathrm{T}}$, and DSM $20346^{\mathrm{T}}$ ) was higher in oxygen-flushed milk compared with other conditions. Concurrently, the time interval between the maximum reduction rate and reaching the final $E_{\mathrm{h} 7}$ was shortened. These effects are probably linked to induction of enzymes involved in oxygen removal and sugar catabolism in oxygenated cultures with consequent production of acetoin/diacetyl and reduction of the pyruvate pool (Neves et al., 2002).

Another effect of oxygen treatment on milk acidification was slowing the rate and time of anaerobic maxima determined for the DL-starter culture and the tested strains. Because bacterial growth was not inhibited by oxygen, the decrease in acidification ability was most probably related to the metabolic changes as discussed above. A slower decrease in $\mathrm{pH}$ at high initial oxygen might be due to further shifts from homolactic fermentation to mixed acid fermentations with formation of acetate, which is a weaker acid $\left(\mathrm{p} K_{\mathrm{a}}=4.76\right)$ than lactate $\left(\mathrm{p} K_{\mathrm{a}}=3.86\right)$.

Milk acidification curves for most of the LAB in this study exhibited diauxic behavior at low initial oxygen conditions (nitrogen flushing) similar to those of untreated milk. These observations contradict previous findings that demonstrated a single acidification rate maximum for Lc. lactis ssp. lactis in nitrogen-bubbled milk (Jeanson et al., 2009). These discrepancies are probably due to differences between the strains and the levels of initial oxygen produced by nitrogen gassing in this study $\left(\mathrm{dO}_{2}=17 \%\right)$ and the study by Jeanson et al. $\left(2009 ; \mathrm{dO}_{2}=0 \%\right)$.

Kinetic parameters of the DL-starter culture A were comparable with parameters determined for the best acidifying and reducing strains isolated for this culture, indicating their additive effect. Thus, the poor reduction ability of Lc. lactis ssp. lactis $\mathrm{CHCC}$ D1 and CHCC D3 was probably compensated by high reducers in the DL-starter culture. Additionally, a common feature of mixed-strain DL-starters is competition between the strains for nitrogenous nutrients. Inhibition of Leu. mesenteroides grown in mixed strain cultures with Lc. lactis have been reported (Bellengier et al., 1997). Hence, prediction of acidification performance of a DL-starter culture composed of individual strains will require extensive knowledge of interstrain relationships during acidification.

\section{CONCLUSIONS}

Acidification and reduction capacity of Lc. lactis and Leu. mesenteroides subspecies in milk were highly variable at the species, subspecies, and strain levels. The decrease in redox potential was highest at the time of oxygen depletion, followed by a more gradual decrease to the final redox values, indicating that both oxygen and biological factors are involved in the reduction process. Two of the Lc. lactis ssp. lactis strains, although having high acidifying power, were unable to decrease the redox potential to negative values. Patterns of acidification curves were generally diauxic, indicating shifts in the metabolic pathways of the LAB. Acidification rate maxima were observed before (aerobic maximum) and after (anaerobic maximum) oxygen depletion, when reduction was completed. Flushing of milk with oxygen slowed milk reduction by all tested bacteria. Concurrently, decreases in acidification rate and delay in acidification time were observed for the DL-starter culture A and most of the bacterial strains. Generally, kinetic parameters of fermentation in nitrogen-flushed milk were not significantly different from standard conditions. This study describes the relationship between milk acidification and redox potential as affected by initial oxygen levels. Knowledge of these factors is important in the dairy industry for standardization of milk acidification processes to shorten acidification time and obtain better sensory characteristics of dairy products. To obtain this knowledge, further genomic and metabolic studies are required to clarify the mechanisms behind bacterial adaptation to environmental changes such as, for example, oxygenation during milk acidification.

\section{ACKNOWLEDGMENTS}

This research was financially supported by and performed in cooperation with the Danish Agricultural and Veterinary Research Council, Danish Dairy Research Foundation (Copenhagen; Project "Cheese RedOx: Optimization of cheese quality by control of the redox potential of milk," J. nr. 3414-09-02561). We thank Chr. Hansen A/S (Hørsholm, Denmark) for providing bacterial strains and cultures.

\section{REFERENCES}

Abraham, S., R. Cachon, S. Jeanson, B. Ebel, D. Michelon, C. Aubert, C. Rojas, G. Feron, E. Beuvier, P. Gervais, and J. De Coninck 2013. A procedure for reproducible measurement of redox potential (E-h) in dairy processes. Dairy Sci. Technol. 93:675-690.

Bellengier, P., J. Richard, and A. Foucaud. 1997. Associative growth of Lactococcus lactis and Leuconostoc mesenteroides strains in milk. J. Dairy Sci. 80:1520-1527. 
Beresford, T. P., N. A. Fitzsimons, N. L. Brennan, and T. M. Cogan. 2001. Recent advances in cheese microbiology. Int. Dairy J. 11:259-274.

Bolduc, M. P., L. Bazinet, J. Lessard, J. M. Chapuzet, and J. C. Vuillemard. 2006. Electrochemical modification of the redox potential of pasteurized milk and its evolution during storage. J. Agric. Food Chem. 54:4651-4657.

Boucher, B., C. Brothersen, and J. R. Broadbent. 2006. Influence of starter and nonstarter lactic acid bacteria on medium redox. Aust. J. Dairy Technol. 61:116-118.

Brasca, M., S. Morandi, R. Lodi, and A. Tamburini. 2007. Redox potential to discriminate among species of lactic acid bacteria. J. Appl. Microbiol. 103:1516-1524.

Brooijmans, R. J., B. Poolman, G. K. Schuurman-Wolters, W. M. de Vos, and J. Hugenholtz. 2007. Generation of a membrane potential by Lactococcus lactis through aerobic electron transport. J. Bacteriol. 189:5203-5209.

Cachon, R., S. Jeanson, M. Aldarf, and C. Divies. 2002. Characterisation of lactic starters based on acidification and reduction activities. Lait 82:281-288.

Caldeo, V., and P. L. H. McSweeney. 2012. Changes in oxidationreduction potential during the simulated manufacture of different cheese varieties. Int. Dairy J. 25:16-20.

Cocaign-Bousquet, M., S. Even, N. D. Lindley, and P. Loubiere. 2002. Anaerobic sugar catabolism in Lactococcus lactis: Genetic regulation and enzyme control over pathway flux. Appl. Microbiol. Biotechnol. 60:24-32.

Jeanson, S., N. Hilgert, M. O. Coquillard, C. Seukpanya, M. Faiveley, P. Neveu, C. Abraham, V. Georgescu, P. Fourcassie, and E. Beuvier. 2009. Milk acidification by Lactococcus lactis is improved by decreasing the level of dissolved oxygen rather than decreasing redox potential in the milk prior to inoculation. Int. J. Food Microbiol. 131:75-81.

Kieronczyk, A., R. Cachon, G. Feron, and M. Yvon. 2006. Addition of oxidizing or reducing agents to the reaction medium influences amino acid conversion to aroma compounds by Lactococcus lactis. J. Appl. Microbiol. 101:1114-1122.

Kowalczyk, M., and J. Bardowski. 2007. Regulation of sugar catabolism in Lactococcus lactis. Crit. Rev. Microbiol. 33:1-13.

Magni, C., D. de Mendoza, W. N. Konings, and J. S. Lolkema. 1999. Mechanism of citrate metabolism in Lactococcus lactis: Resistance against lactate toxicity at low pH. J. Bacteriol. 181:1451-1457.

Martin, F., R. Cachon, K. Pernin, C. J. De, P. Gervais, E. Guichard, and N. Cayot. 2011. Effect of oxidoreduction potential on aroma biosynthesis by lactic acid bacteria in nonfat yogurt. J. Dairy Sci. 94:614-622.

Martin, F., N. Cayot, A. Marin, L. Journaux, P. Cayot, P. Gervais, and R. Cachon. 2009. Effect of oxidoreduction potential and of gas bubbling on rheological properties and microstructure of acid skim milk gels acidified with glucono-delta-lactone. J. Dairy Sci 92:5898-5906.

Marty-Teysset, C., C. Posthuma, J. S. Lolkema, P. Schmitt, C. Divies, and W. N. Konings. 1996. Proton motive force generation by citrolactic fermentation in Leuconostoc mesenteroides. J. Bacteriol. 178:2178-2185.

McSweeney, P. L. H., V. Caldeo, A. Topcu, and D. R. Cooke. 2010. Ripening of cheese: oxidation-reduction potential and calcium phosphate. Aust. J. Dairy Technol. 65:178-184.

Morris, J. G. 2000. The effect of redox potential. Pages 235-250 in The Microbiological Safety and Quality of Food. B. M. Lund, T. C. Baird-Parker, and G. W. Could, ed. Aspen Publishers Inc., Gaithersburg, MD.

Neves, A. R., W. A. Pool, J. Kok, O. P. Kuipers, and H. Santos. 2005. Overview on sugar metabolism and its control in Lactococcus lactis - The input from in vivo NMR. FEMS Microbiol. Rev. 29:531-554.

Neves, A. R., A. Ramos, H. Costa, I. I. van Swam, J. Hugenholtz, M. Kleerebezem, W. de Vos, and H. Santos. 2002. Effect of different NADH oxidase levels on glucose metabolism by Lactococcus lactis: Kinetics of intracellular metabolite pools determined by in vivo nuclear magnetic resonance. Appl. Environ. Microbiol. 68:6332-6342

Nordkvist, M., N. B. Jensen, and J. Villadsen. 2003. Glucose metabolism in Lactococcus lactis MG1363 under different aeration conditions: Requirement of acetate to sustain growth under microaerobic conditions. Appl. Environ. Microbiol. 69:3462-3468.

Ramos, A., J. S. Lolkema, W. N. Konings, and H. Santos. 1995. Enzyme basis for $\mathrm{pH}$ regulation of citrate and pyruvate metabolism by Leuconostoc oenos. Appl. Environ. Microbiol. 61:1303-1310.

Rezaïki, L., G. Lamberet, A. Derre, A. Gruss, and P. Gaudu. 2008 Lactococcus lactis produces short-chain quinones that cross-feed Group B Streptococcus to activate respiration growth. Mol. Microbiol. 67:947-957.

Schreyer, A., M. Britten, J. M. Chapuzet, J. Lessard, and L. Bazinet. 2008. Electrochemical modification of the redox potential of different milk products and its evolution during storage. Innov. Food Sci. Emerg. Technol. 9:255-264.

Starrenburg, M. J., and J. Hugenholtz. 1991. Citrate fermentation by Lactococcus and Leuconostoc spp. Appl. Environ. Microbiol. 57:3535-3540.

Tachon, S., J. B. Brandsma, and M. Yvon. 2010. NoxE NADH oxidase and the electron transport chain are responsible for the ability of Lactococcus lactis to decrease the redox potential of milk. Appl. Environ. Microbiol. 76:1311-1319.

Tachon, S., D. Michelon, E. Chambellon, M. Cantonnet, C. Mezange, L. Henno, R. Cachon, and M. Yvon. 2009. Experimental conditions affect the site of tetrazolium violet reduction in the electron transport chain of Lactococcus lactis. Microbiology 155:2941-2948. 